\title{
Influence of New Technologies in E-Commerce
}

\author{
Paul George OPRESCU \\ The Bucharest University of Economic Studies, Doctoral School of Economic Informatics \\ oprescugp@gmail.com
}

Easy to use, but difficult to understand and master, technology leaves its mark in almost every field of our contemporary society. Commerce is one of the most widespread concepts in history, being the bedrock of human evolution through its various forms and practices. Combining the two will help humanity reach new heights in terms of online trading and understanding customer needs. The need for face to face interaction between the buyer and the supplier has been completely removed with the emergence of e-commerce and the development of ecommerce platforms. Influenced by both external and internal factors, to gain success, an online platform captures the attention of buyers, analyzing their behavior through data processing algorithms in order to obtain business information needed for the company's business strategy. With Big Data and Data Mining, the profile of any consumer is projected directly into the platform, thus communicating the necessary information to predict the behavior in future platform visits.

Keywords: E-commerce platforms, E-Business: Business to Business (B2B) \& Business to Consumer (B2C), Supply-Chain Management, Drop shipping, IoT and Data Mining, Elasticsearch.

DOI: $10.12948 /$ ei2019.01.03

1

\section{Introduction}

Due to recent technological changes, there may be difficulties in analyzing an ecommerce platform and determining the key factors that lead to a successful business that differentiates from the ones already on the market.[1] An electronic business is the exchange of services and products via the Internet between several types of consumers and businesses in order to make profit. In most cases there is ambiguity when involving this type of business activity, the concept being reduced to online shopping, consumers not understanding the mechanics that reside behind. Among the usual consumers, other companies and entrepreneurs with a vision of the market also participate in this type of commerce. Starting from the layout of the page and the technical characteristics, reaching the executive board that decides the future of the business, all elements are interconnected and communicate with each other through business information. Managerial skills and creativity are important in an e-business, but in order to maintain its integrity and stability, the investment must be on the same level as the results, combining resources to deliver a product that meets the market requirements being a bold and difficult process and can have many financial consequences. The rapid evolution of technology provides a competition to those who want to participate in this market. Everything revolves around the online concept, which is predominant in any field and is the key to a long-lasting business expansion. There is no person who does not have access to an Internet connected device nowadays and this predisposition to InternetOf-Things is the future of humanity towards an interconnected society. Activities that were going on every day with some difficulty have now been replaced or assisted by technology. Due to this technological advancement, ebusiness is in the best development and integration period. At marketing level, there is no need for a direct face to face relationship between the buyer and the supplier, all the products being highlighted directly through the e-commerce platform. Over time, people's interaction with e-commerce platforms has made it possible for computer science engineers to refine the analysis and data mining algorithms responsible for a better 
understanding of the consumer's needs and transforming them into services and design. At the heart of an electronic business, the efficient use of both hardware and software resources in line with customer requirements is essential in maintaining flexibility and a place on the market.

\section{Factors that influence the success of e- commerce platforms}

The most common forms of e-commerce are B2B or business-to-business and B2C or business-to-consumer. In business-toconsumer, customers acquire through ecommerce platforms products of different types and forms according to their needs. There are many factors that influence the customer's interest and determine the platform's quality factor. Used by the most successful companies, inspiring professionalism, the simplicity of the design is one of the most important aspects of the technological era. The consumer has a welldefined goal when accessing the web page, to purchase the product as quickly as possible without being distracted by the other elements of the page, regardless of their complexity. Behind any seemingly simple application for the average consumer, there are concepts, ideas, algorithms and technologies that together make up the complexity of the platform. The interface through which the user accesses the site must be user-friendly and intuitive and the engine behind the design should ensure its functionality. Among the main user-friendly features a web site contains: the search bar and the algorithm behind it that helps the buyer to find results as close as possible to the product they desire; search filters by price, categories, subcategories and other technical or descriptive specifications; product-level details and placement on the page; simple page colours to ensure easy access; payment methods through which the consumer can complete the order: card, bank transfer, cash on delivery, payment order; a feedback page for notes and reviews. The quality of the services offered when talking about ecommerce is not only determined by the technical support of the platform, but also by the later assistance by the company in case of delivery errors, defective products, even technical failures of the platform. The best way a company tests the competence of their software is through consumers who use it and offer positive or negative feedback. The question that the executive power of the ebusiness firm should discuss is what determines a consumer to buy a product online. The environment in which a person spends most of their time is the comfort zone and is therefore worthy of exploitation by any businessman. Accessibility and convenience are very important factors in every person's life and motivate them in achieving their daily activities easily, without going through a filter of thought. The availability of the platform at any time of the day highlights the superiority of the online concept over an ordinary shop. Furthermore, the individual is more likely to access the platform from anywhere regardless of whether they are currently seeking to purchase a product or just to verify certain products for subsequent purchases. A vice of people everywhere in the contemporary world is access because of habit. It plays an important role in the development of online platforms and it is what every entrepreneur wants: the personal life of a large number of people to become interconnected with his business. A business always revolves around one very important element, namely the price of the services or products offered. The online environment has an advantage over traditional stores that do not consume financial resources on employees and use automated sales and purchasing systems. Thus, operational costs are directed towards consumers by making promotions and reducing prices. Consumers are in most cases also influenced by the pricing and with the emergence of Internet comparison tools, transparency is inevitable. Through online stores, the range of products and services is unlimited, providing the buyer the power of choice. Here comes the availability of each company and how it manages its stocks. There is also the possibility of a monopoly on e-commerce platforms, which can be exploited at different 
levels, both at regional level and according to the types of products offered. Big companies such as Amazon and AliExpress are among the largest companies fighting for supremacy while developing new innovative projects. Their position on the market is the biggest advantage that these companies can have and most small platforms integrate their products and services through these successful platforms, hoping they will one day launch on their own terms. It is never known when the seats already occupied in the top will again be free to allow new enthusiasts and entrepreneurs to prepare and enter the ecommerce market.

The more profitable a company is, the more and more the business grows. [5]. In order to make a profit, customers must have as many payment methods as possible to encourage them to start online trades. If the platform expands globally, it must also embrace other payment methods in those countries to ensure that no customer has trouble purchasing a product. That is why partnerships with banks and other financial service providers are being developed to ensure this compatibility. The most common form of online payment is by credit card. The consumer completes his card details, and through the supplier with which the platform is associated and to which the customer holds the card, the purchased product is paid. If there is a large amount of money in the payment of business services between companies, the same banking utilities available between the company accounts are used. Another equally popular method is through the mobile phone, by integrating the card in a banking application or directly through the mobile service. The cost will then be transferred to the customer's invoice, where he usually pays the subscription or mobile service. Similar to this method is the electronic wallet or E-wallet that includes in an application the personal data of the consumer and a sum of money. The electronic wallet also works with NFC or near field communication technology that allows the user to simulate the card for instant money transfer. The prepaid card is another method of payment very often used by those who do not yet have a regular credit card. This type of card contains a fixed amount of money, is usually offered as a ticket or coupon for later use when purchasing a product. This method offers increased security since the consumer does not store personal data, card payment being only a digital amount that can be offered in exchange for products in the online environment, using a unique code. With these prepaid cards, discount cards offered to manipulate the consumer in the purchase of products can also appear. A strategy of the big companies where the demand decreases is to transform the consumer into their own product by making these marketing campaigns with discounts and discounts. The risk factor for losing money paid when purchasing a product through an online payment method is very low. Some customers prefer to pay in the traditional form with cash when the product is delivered to a specified address. This payment method transfers the effort to the courier company that deals with the security of both the products and the financial one. Thus, the costs of the e-commerce company will be higher. 


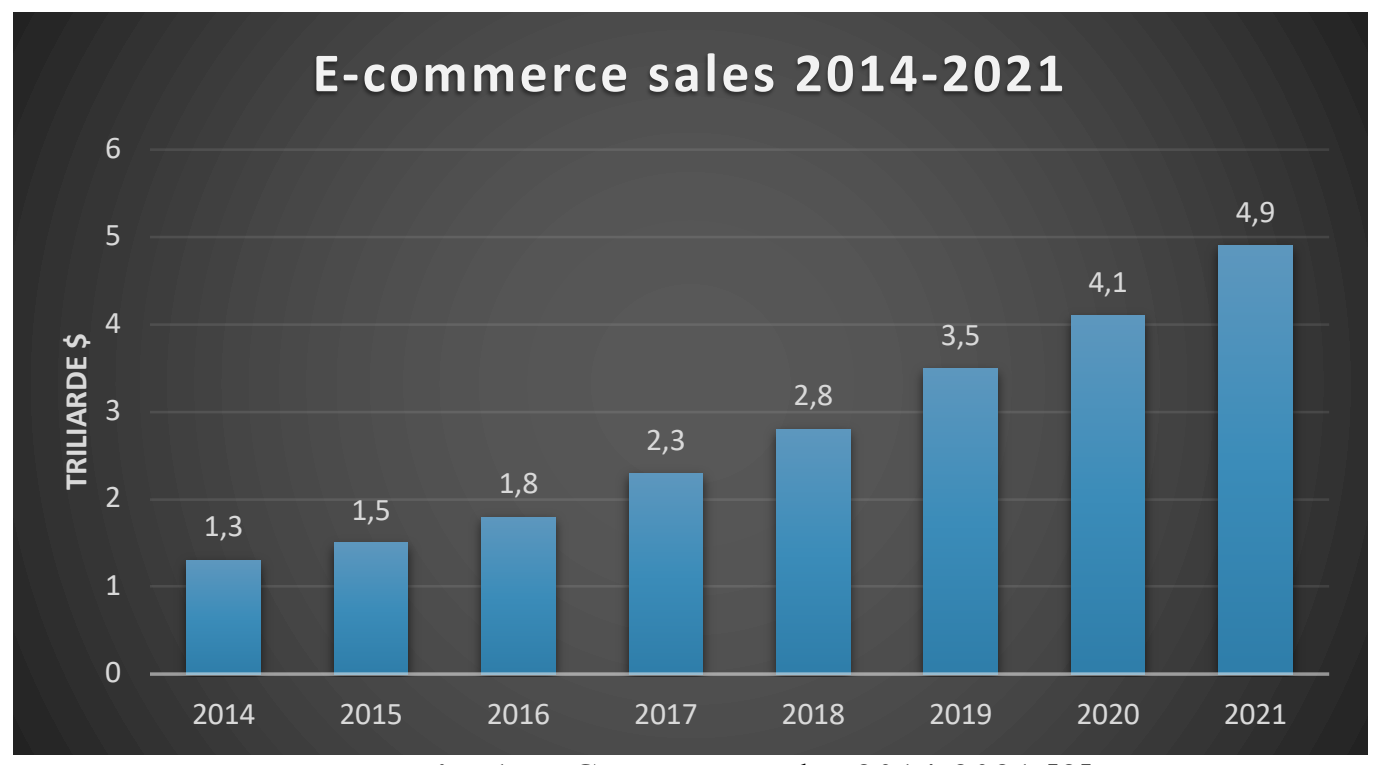

Fig. 1. E-Commerce sales 2014-2021 [2]

An electronic business has the ability to grow exponentially due to scalability on the Internet. Scalability is meant to promote the company's unique services and products through online marketing and social platforms. The number of sales on ecommerce platforms has grown exponentially over time and is expected to reach $\$ 4.9$ trillion by 2021 (Fig. 1). Online marketing is much smarter than its precursor, targeting and analyzing precisely the specific needs of the consumer over time and personalizing his searches, as well as exposing similar results in the form of advertisements on social media platforms. Man is social by nature, so his need for interaction with other people can also be realized through personal computers, mobile phones, tablets on social networks. Due to the validity offered, like the e-commerce platforms, the offers about their products and services can be displayed every time the buyer accesses their social platform account. The intention is not relevant, as an individual does not necessarily want to purchase a particular product at a certain time. He is influenced by the intelligent positioning of the offers in an online space very often accessed by him.

\section{Supply-Chain Management and e- commerce models}

Like any traditional or electronic form of commerce, the management of services, information and products, their flow, the way of creation, storage and the entire inventory process is included in the concept of SupplyChain Management.[3] The flow of information is as important as that of the products, all the activity of storage, transportation and transformation of the products being managed by the capacity of efficient planning of activities due to the information between the participants. The Supply Chain itself is like an invisible chain between buyers, retailers, wholesalers, distributors, suppliers and manufacturers. The lack of communication and organization among the participants leads to the creation of a Bullwhip effect, which represents the fluctuations between supply and demand within the Supply Chain.[4] The role of a retailer is determined by how it performs its activity of providing services and products. This mode seriously affects the characteristics of the respective business, as the approach is a very important factor in any kind of economic activity. In the drop shipping model,[6] the owner of the online store does not physically own the products. They are stored at the supplier and delivered when an order is placed through the e-commerce platform owned by the owner. The owner thus buys the product from the supplier and automatically delivers it to the consumer, without interacting visually with the product. An advantage of this model is the very low investment costs, an individual being able to 
launch such a platform without a large sum of money. The purchase of a product from the supplier to the store is made only when the transaction between the buyer and the platform has been completed and the money is already in the owner's possession. The launch of an electronic business of this type is easily achieved due to the lack of stock. The owner does not pay the costs of accounting, storage and maintenance, packing, delivery and return and there is no need to purchase products continuously to maintain the available stock. The business can be maintained through a simple computer or laptop, so the costs for the equipment are almost nonexistent. An electronic dropshipping business can work from anywhere, the only prerequisite being internet access and a bespoke imagination to detach yourself from the competition and impress. The types of products and services that buyers can view on such a platform are available to suppliers. When a supplier launches a new product, at no additional cost, the owner can upload it to the platform. Every business has its disadvantages and although the costs of maintenance and equipment are low, the profit can suffer at any time depending on the fluctuations in the market. If the manufacturer suffers a negative fluctuation, it will recover later, compared to the drop shipping business, which is based on the manufacturer, which will result in a major loss or even permanent closure of the business. If the business has its own inventory, it is easier to track. In an electronic business of this type, because the products can be delivered from different warehouses it is quite difficult to see if they are available at any time and can be delivered directly to the consumer.

Another common problem in such a business is the cost of the products the consumer orders from different suppliers. Thus in a single order from 3 different suppliers he pays the same amount as for an order of 3 products from a single supplier, and the owner suffers as he pays more for each order. If the suppliers encounter difficulties in delivery, whether it is a delay or complete cancellation of the order, they will not answer for it and the owner will have to cover the costs. Its reputation may be unfavorable as a result of such an action and it is not always in its control as the suppliers carry on their commercial activity.

The traditional method of sale purchase has several advantages and disadvantages over the dropshipping model, one of the advantages being the scalability of the profit depending on the quantity of products sold. A supplier pays only for the raw material and the production cost of the product, which is much lower than the price at which it is later bought by the retailer. Stock maintenance is much easier to do, knowing at all times the amount of stock available and the amount needed to be added to maintain it. In dropshipping everything is based on the availability of the supplier and it remains within his reach how many products you can sell to the buyers. That is why the entrepreneurial skills of a dropshipping owner are what make the difference in such a business and its ability to maintain direct and permanent contact with product suppliers. If this connection is maintained constantly and there is no conflict of interest and lack of communication between the supplier and the owner, he will have less costs in the event of a delivery problem, by quickly resolving the problem or even avoiding it in time. The owners of a traditional e-commerce platform are their own suppliers and are therefore not responsible for the retailers' organizational problems. Another common method is the outsourcing of sale-purchase services. The retailer does not want to be responsible for this process of purchasing and delivering the products and thus uses the services of another company to deal exclusively with the selling process.

\section{Influence of technology on e-business}

The technology leaves its mark in online media through the multitude of data it obtains as a result of consumer interaction with ecommerce platforms. Their preferences can be registered, from color, type, region, size to price, payment method, quantity, thus managing the stock and validity of the products, streamlining the sale-purchase process. The consumer experience is 
improved by trying to understand the behavior of the company. The ability of the executive power of the company that owns the ecommerce platform is assisted by these data collection and analysis technologies, processed with the help of the Business Intelligence and IT departments. Although different departments, there is a connection between them within any company. Removing the threshold between the two and combining activities to improve the decisionmaking process is one of the most difficult and daring challenges of the technological era. Both internal and external applications are made by IT technicians and engineers. The notion of business intelligence is the ability of the company to understand in what direction it's going, both internally, financially and in relation to the public, and what are the measures to be taken towards the evolution of the company. The data is processed and stored in different multidimensional databases, which will be later transformed into business information. This information is visible through statistical and graphical data of different types, the whole idea being encapsulated in the notion of interactive dashboard. The dashboard provides the executive with the entire current situation and forecasts about what direction the company is moving towards, depending on the existing factors or the potential opportunities that it may have if it changes its strategy. Therefore, the business intelligence department does not help to increase the profit of the company directly, only the decision-making power is drastically influenced and can be the factor that differentiates and detaches from the competition. In this area, the notion of EDI or Electronic Data Interchange transactions is very widespread.[7] EDI means the possibility of a company sending electronic products and services to another company or exchanging business information within it. Due to the electronic format, paper is not required for printing the document, keeping a record of the payment order directly on the computer. Small companies do not always have the financial capacity to implement such technology and have no interest in the future.
They can decide to halve the effort and turn this process into a manually assisted one. Thus the documents transmitted by other companies will not be automatically inserted into the system, they will be printed and subsequently introduced by manual intervention of the employees. The hybrid way of working is not a new technological process and is caused only by the inability of the company to work according to the standards, the robust adaptation being needed instead. An example of such a process would be when a customer launches an order, and it is taken over by an operator from within the company via email or paper. The operator enters the data in the manual system through a calculation system and generates an electronic invoice that will be transmitted to the customer. Through EDI this whole process is automated, so that when the customer has sent the order, the invoice is registered and the invoice is issued without manual intervention. This can increase the cost of maintaining such an automated system in favor of the time that would otherwise be invested by the employees of the company and of the human errors that may arise from the manual operation. The complexity in such a process in case of an error can lead to the cancellation of the order, unwanted complaints or even lost businesses depending on the gravity of the situation.

We live in a world dominated by more and more technological devices and this is not breaking news. The mobile phone is the most widely used tool in one's personal life, as more and more people make this transition from computer to phone. Much more accessible and easy to use, with increased security and portability, it is the target of any competitor in the electronic business market and encapsulates the main marketing strategy. The quality of the services offered by mobile phones is increasing exponentially, thus providing the most favorable environment for the development of electronic business and the strategies necessary to maintain the public interest. With the advent of $4 \mathrm{G}$, there has been an explosion of convenience and speed with which a user accesses information through his device.[8] 
The power of connectivity does not stop here, internet on mobiles reaching unparalleled speeds with the advent of the highly anticipated 5G technology. Although many say that mobile speed has already reached a level where any kind of growth is no longer visible in everyday life, the evolution of small things over time is the reason why technology has reached the level it is today and will continue to surprise in the future. Humanity does not perceive the evolution of technology over time, because we are too much influenced by the present and we want all things to happen in large quantities and at once. The progress of technology is achieved in small steps and it is quite fast regardless of the ever dissatisfied public opinion. Comfort and habit is the most difficult factor for any company, human nature being difficult to impress, everyone's life being dominated by monotony, interest being difficult to capture. Furthermore, e-business companies no longer focus solely on public opinion and try to personalize them through artificial intelligence and data processing methods. The moment a person accesses this platform, it adapts according to the preferences of the consumer and not those of the current trend of the global population. Through repeated accesses the algorithm is adjusted according to the person who owns the platform. But the technology went even further through smart browsers that keep the profile of each one embedded in them through HTTP cookies. These is data that remains on the computer or mobile devices of each user and subsequently help the accuracy of the algorithm that tries to meet the needs of the consumer. The data can be used later on for other, less positive purposes and sold to big companies for marketing, being a violation of privacy and personal space. Many companies have been affected with the appearance of the GDPR or General Data Protection Regulation, which is a security legislation developed by the European Parliament for the protection of EU citizens personal data. Facebook, which is a monster in the field of social networks, suffered and is still under investigation regarding the security of personal data that should not be available to anyone and is the absolute symbol of the privacy of every person that should not be violated. So there is a sensitivity when it comes to data being collected through e-commerce platforms, and companies need to treat them carefully to protect the integrity and security of its customers. Some platforms, however, do not go so far with the profiling of each consumer and do not have to worry because the data collected are obtained from a more superficial analysis, the only interest being to introduce the user in a certain category of consumers who purchase certain types of products. . The personalization of a customer's experience, however, differs from one platform to another by the level of depth at which the personal data is processed. However, the buyer can decide what information to send to the platform by selecting options or by communicating directly with a chat bot that simulates the behavior of an online employee. Through a discussion with it, the algorithm decides what the buyer needs and the data he has provided following the discussion.

\section{Agile in e-business}

An agile method encompasses all the iterative processes by which a software product can be developed and tested in a fast and efficient way to comply with all customer requirements. [9] This principle implies that the testing and development of the ecommerce platform takes place at the same time as opposed to the traditional methods where the testing often takes place at the end of the development cycle. Documentation is not an objective of the agile method of developing a software application, the process focusing on solving problems as quickly as possible and implementing the required solutions. The customer also has the opportunity to intervene throughout the cycle to provide feedback or to bring new requirements regarding his software product. Errors are also handled at the same time when testing, programmers and testers working together to quickly and efficiently complete a small step in this long process. It is divided into individual models assigned to several 
programmers who work competitively without a certain structure. A disadvantage would be that each development process has a period of several weeks called sprint without being allocated long-term planning time with a strict deadline until certain conditions should be met before the next sprint. If the errors have not been resolved, the tasks will be reassigned and the next sprint will be much more loaded and it will be necessary to repair them before continuing the project. Throughout the development period of the software product there is a direct connection between the developers and the client to ensure that the project ultimately complies with the requirements and specifications required or subsequently modified. Therefor at the end of each sprint a UAT or User Acceptance Testing takes place where the client tests their product to make sure the software is behaving as specified.[10] At the opposite pole in the traditional method of product testing at the end of the development cycle, errors can be critical and difficult to understand compared to the agile methods where they are solved early and are easy to be found, having a narrower area than can be detected. These tests are designed to cover all the cases that a customer goes through when using the application. In the case of Business To Business, the client is in a direct relationship with the company providing the services. An example would be a company that provides financial services and wants an ERP internal resource management application. If the company has a specialized department for these operations it would not be necessary to license a product for management. Otherwise, as the application is developed through agile methods, the first level of support of the financial company is in permanent contact with the team of the supplier company to ensure that the application complies with their specifications which are more than complex due to the field in which it operates. A difference would be in Business To Consumer where the customer did not directly ask the company to implement a certain specification, he being just an average consumer who wants to buy a product. It is up to companies to understand the behavior of consumers and forecast their preferences over time by understanding the trends, but also by data collection algorithms and transforming them into business information needed to make decisions. The buyer is not interested in how the e-commerce platform works in the background. The platform must be complex, yet simple at the same time and easy to maintain according to the new requirements that intervene throughout the cycle. There is a way in which consumers can file complaints or notices the company by phone or email, but it is not a direct link in comparison to a customer whose application was a software product intended for personal use. Another disadvantage of the agile method would be when there is a confusion between what the consumer wants and what the company implements. The technology allows for such confusion to be eliminated through analysis and forecasting, but the human factor and the electronic business market are unpredictable and not always in line with what the company is trying to promote. In conclusion, the trends change from day to day, the conditions and the market offering a tough and competitive environment for companies that want to conduct ecommerce.

\section{Types of e-commerce platforms}

The question that any individual should ask themselves before entering the field of electronic business is what kind of activity they want to maintain and what kind of ecommerce platform they should use. It can provide services and products to other companies and is therefore aimed at businessto-business or ordinary consumers through business-to-consumers. The type of ecommerce platform according to the needs of each business owner can be chosen between two categories: with payment or free of charge.[11] In general, to initiate an ecommerce platform, you must follow a few steps throughout this process, which the paid platforms provide without effort from the payer. E-commerce payment platforms offer help and support for any problem or error 
encountered by the user during the subscription. The installation does not require effort from the user, nor any technical knowledge of programming, so that in the future there is no need for personal technical involvement or a developer to guarantee the continuity and maintenance of the web site. The security does not depend on the user and it is strictly the responsibility of those who offer these web hosting services. The page design does not start from 0 , and the user can choose from a variety of themes and colors depending on the preferences. The only problem with this type of customization is that other e-commerce sites can use the same theme. Therefore, the flexibility of design and other basic technical elements are not within the reach of the user and are limited to what the web service providers already offer. Another disadvantage would be the monthly costs if the company does not make a profit. The user is also connected to the host company of the e-commerce platform, and in case it loses its popularity, it will also close the e-commerce platform of the user. Those who want to develop a fast and easy e-commerce platform and have the necessary financial capabilities usually opt for such an ecommerce platform for their business. For those who want to test their technical and entrepreneurial capabilities, there are free ecommerce platforms, where users have control over the resources and restrictions of the site they create. There is no external support for the user, but there is no need for a monthly payment or a certain behavior or service to be delivered on a monthly basis. For site maintenance, however, extensive programming techniques are needed, the level of difficulty being regulated by how complex a user wants to personalize their website and to attract customers through its uniqueness. The solution to pay for an e-commerce platform is therefore favorable for those who do not want to become technically involved in the platform and benefit from support from the company that provides the services and for programming enthusiasts who want to develop a unique website, customizable to the smallest detail, they opt for a free platform.
The best free open source e-commerce platform that is available for anyone to make improvements and share them with the rest of the participants is Magento.

Magento is an open-source e-commerce platform written in PHP, initially developed by Varien Inc. and later acquired in 2018 by Adobe for $\$ 1.68$ billion to integrate with their CMS platform, Adobe Experience Cloud. It is divided into two types of platforms: Magento Open Source and Magento Commerce.[12] Magento Commerce is the on-premise version of the platform-as-a-service type that encapsulates through its architecture all the tools and services needed to develop an electronic business in an agile context. This creates a unique shopping experience by promoting dynamic products according to the consumer profile and assists him through a search engine using Elasticsearch.[13] Elasticsearch is responsible for correcting and interpreting the words and guiding the user in searching for the desired product. Installing such a search engine is quite affordable with default settings and does not require extensive programming knowledge. Behind such technology, however, there is a high complex engine for advanced and fast searches, ready to be incorporated into any kind of application. Once the user is able to understand the main concepts of this search engine, productivity increases effortlessly and extremely quickly. Traditional databases are not designed for complex text searches and they certainly do not have a high performance when it comes to structures or information coming from outside them. Queries that would take a few seconds using SQL would run through Elasticsearch in just a few milliseconds, thus increasing the runtime exponentially. Using an e-commerce platform does not have to be a long process that takes too much time for the consumer to use. The customer logs on to the platform to purchase products or services as quickly as possible, and their search is an essential thing in attracting consumers to the e-commerce site. The positioning of the search bar within the page is an important factor being the first thing that the consumer uses, not knowing in 
most cases what he wants to buy. The platform assists him in searching for the desired product through the back-end algorithms that analyse his searches and propose similar products. Elasticsearch engine design is much simpler than relational databases that contain tables, rows, columns, fields, and logical schemas.[14]

\section{Conclusions}

Trade was among the main activities of mankind, which brought progress and prosperity together with its opportunities. With the invention of the Internet and the possibility of developing an online business, the benefits of those who participate in online transactions have grown exponentially. Both consumers and entrepreneurs interact more easily through e-commerce platforms that have replaced traditional trade methods. Either developed behind a home computer or combined with traditional means of production, the e-business can successfully capture the target market if the idea is in line with the goals. New data analysis technologies and algorithms allow any company to predict consumer behaviour, to understand the needs and assist the executive power in choosing the right strategies. The design of web pages must be in a position to inspire attractiveness and trust in the services provided by the e-business. The smallest detail counts when you participate in a developing market where everyone wants to get a place in the train of innovation and future. Although we are aware of the presence of technology and its evolution, the human mind does not realize how fast technology grows and engulfs ours society over time.

\section{References}

[1] James Morrish; 4 Noiembrie 2015; What is E-Commerce? An introduction to the Industry [Online]. Available: https://feinternational.com/blog/what-ise-commerce-an-introduction-to-theindustry/

[2] Aaron Orendorff; 14 Feb 2019; Global Ecommerce Statistics and Trends to Launch Your Business Beyond Borders
[Online],

Available:

https://www.shopify.com/enterprise/glob al-ecommerce-statistics

[3] Wikipedia;2019; Supply-chain management [Online] Accessed 12 Ian 2019, Available: https://en.wikipedia.org/wiki/Supplychain management

[4] SCRC SME; 2 Aprile 2017; What is Supply Chain Management (SCM)? [Online], Available: https://scm.ncsu.edu/scmarticles/article/what-is-supply-chainmanagement-scm

[5] Paymentwall Team; 27 Aprilie 2016; Types of payment methods for ecommerce [Online], Available: http://blog.paymentwall.com/guides/type s-of-payment-methods-for-ecommerce

[6] Mark Hayes, Andrew Youderian;The Ultimate Guide to Dropshipping [Online];Accesat 15 Ian 2019, Available: https://www.shopify.com/guides/dropshi pping/understanding-dropshipping

[7] The balance small business;Electronic Data Interchange (EDI) Transaction Overview; [Online] Accessed 25 Ian 2019, Available: https:/www.thebalancesmb.com/electron ic-data-interchange-edi-2221329

[8] netscribes.com(Sourav Mukherjee, Andrew Garvin); 5 Iunie 2018; 5 Emerging technology trends in ecommerce [Online], Available: https://www.netscribes.com/ecommercetechnology-trends/

[9] Guru99; 2019; Agile Model \& Methodology: Guide for Developers and Testers [Online], Available: https://www.guru99.com/agile-scrumextreme-testing.html

[10] Technopedia; 2019; User Acceptance Testing (UAT) [Online], Available: https://www.techopedia.com/definition/3 887/user-acceptance-testing-uat

[11] AAAMAZING websites ; 2011-2017; Free vs. Paid e-Commerce Solutions Which One is Right for You? [Online], Available:

https://www.aaamazing.com.au/86-free- 
vs-paid-e-commerce-solutions-whichone-is-right-for-you.html

[12] Wikipedia; 2019; Magento; Accesat 29 Ian 2019[Online], Available: https://en.wikipedia.org/wiki/Magento

[13] Elasticsearch B.V.; 2019; The Heart of the Elastic Stack [Online], Available: https://www.elastic.co/products/elasticsea $\underline{\mathrm{rch}}$

[14] John Vanderzyden; 1 Septembrie 2015; What is Elasticsearch, and How Can I Use It? [Online], Available: https://qbox.io/blog/what-is-elasticsearch

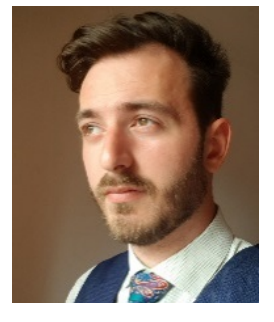

George Paul Oprescu is currently holding a bachelor degree in Economic Informatics after finishing in 2016 the Faculty of Cybernetics, Statistics and Economic Informatics and a master's degree in database management finished under the same faculty in 2018. A Phd Student at The Doctoral School of Economic Informatics and a Database Developer for IHS Markit, his main fields of study are Database development, Economy, E-commerce, agile development and Business Intelligence. 